\title{
The interplay between the hippocampus and amygdala in regulating aberrant hippocampal neurogenesis during protracted abstinence from alcohol dependence
}

\author{
Chitra D. Mandyam* \\ Committee on the Neurobiology of Addictive Disorders, The Scripps Research Institute, La Jolla, CA, USA
}

\section{Edited by:}

Nicholas W. Gilpin, LSUHSC-New

Orleans, USA

Reviewed by:

Kimberly Nixon, University of Kentucky, USA

Scott E. Hemby, Wake Forest University School of Medicine, USA

\section{*Correspondence:}

Chitra D. Mandyam, Committee on the Neurobiology of Addictive Disorders, The Scripps Research Institute, 10550 North Torrey Pines Road, SP30-2400, La Jolla, CA 92037, USA

e-mail: cmandyam@scripps.edu
The development of alcohol dependence involves elevated anxiety, low mood, and increased sensitivity to stress, collectively labeled negative affect. Particularly interesting is the recent accumulating evidence that sensitized extrahypothalamic stress systems [e.g., hyperglutamatergic activity, blunted hypothalamic-pituitary-adrenal (HPA) hormonal levels, altered corticotropin-releasing factor signaling, and altered glucocorticoid receptor signaling in the extended amygdala] are evident in withdrawn dependent rats, supporting the hypothesis that pathological neuroadaptations in the extended amygdala contribute to the negative affective state. Notably, hippocampal neurotoxicity observed as aberrant dentate gyrus (DG) neurogenesis (neurogenesis is a process where neural stem cells in the adult hippocampal subgranular zone generate DG granule cell neurons) and DG neurodegeneration are observed in withdrawn dependent rats. These correlations between withdrawal and aberrant neurogenesis in dependent rats suggest that alterations in the DG could be hypothesized to be due to compromised HPA axis activity and associated hyperglutamatergic activity originating from the basolateral amygdala in withdrawn dependent rats. This review discusses a possible link between the neuroadaptations in the extended amygdala stress systems and the resulting pathological plasticity that could facilitate recruitment of new emotional memory circuits in the hippocampus as a function of aberrant DG neurogenesis.

Keywords: chronic ethanol, vapor induced dependence, self-administration, subgranular zone, hippocampus, BrdU

\section{NEUROGENESIS IN THE ADULT DENTATE GYRUS}

Accumulating evidence over the past four decades shows that forebrain neural stem cells populate two main areas, the subventricular zone of the lateral ventricles and subgranular zone (SGZ) of the hippocampal dentate gyrus (DG; Figure 1), where they give rise to neurons throughout adulthood. Adult neurogenesis is found in these forebrain regions in all mammalian species examined, including humans (Eriksson et al., 1998; Curtis et al., 2007), and may serve to replace cells damaged by brain disorders, such as addiction to drugs of abuse and alcohol. Whether they replace dying or diseased cells and if so to what extent are questions currently receiving intense research focus.

Adult neurogenesis in the hippocampal DG plays an important role in maintaining hippocampal plasticity. The process of neurogenesis involves stem-like precursor cells (type 1 cells) that proliferate into preneuronal progenitors (type 2 and type 3 ), which in turn differentiate into immature neurons and eventually mature into granule cell neurons (GCNs; Kempermann et al., 2004; Abrous et al., 2005; Figure 1). A large proportion (>80\%) of hippocampal progenitors migrate a short distance to become GCNs in the DG (Kaplan and Hinds, 1977; Hastings et al., 2001), and there is evidence demonstrating functional incorporation of the newly born neurons in the DG (Gould et al., 1999; Shors et al., 2002; Aimone et al., 2006). For example, DG neurogenesis has been implicated in the maintenance of hippocampal networking (Aimone et al.,
2006; Clark et al., 2012; Lacefield et al., 2012) and assists with certain behaviors that depend on the hippocampus (Feng et al., 2001; Deisseroth et al., 2004; Schmidt-Hieber et al., 2004; Kim et al., 2012) and is critical for encoding new information by facilitating the formation of new memories that assist with hippocampusdependent behaviors (McHugh et al., 2007; Bakker et al., 2008; Clelland et al., 2009; Aimone et al., 2011; Sahay et al., 2011).

Dentate gyrus neurogenesis is also strongly regulated by stress and glucocorticoids (Cameron and Gould, 1994; Mirescu and Gould, 2006; Oomen et al., 2007; Snyder et al., 2011). Conversely, DG neurogenesis regulates the secretion of glucocorticoids in response to stress (Snyder et al., 2011). This is important because the hippocampus provides negative control of the hypothalamicpituitary-adrenal (HPA) axis, and DG neurogenesis regulates hippocampal regulation of the HPA axis (Snyder et al., 2011), although the circuitry mediating this effect is not well understood. Furthermore, the role of the glutamatergic system in the development and maintenance of DG neurogenesis is well documented (Cameron et al., 1995). For example, $N$-methyl-D-aspartate (NMDA) receptor activation reduces the proliferation of neural precursors in a normal state, and blockade of NMDA receptors increases the birth and survival of neural precursors in the DG, suggesting that neuronal inputs into the hippocampus regulate DG neurogenesis (Figure 2). Furthermore, recent evidence demonstrates compromised HPA axis activity (Richardson et al., 2008), altered 


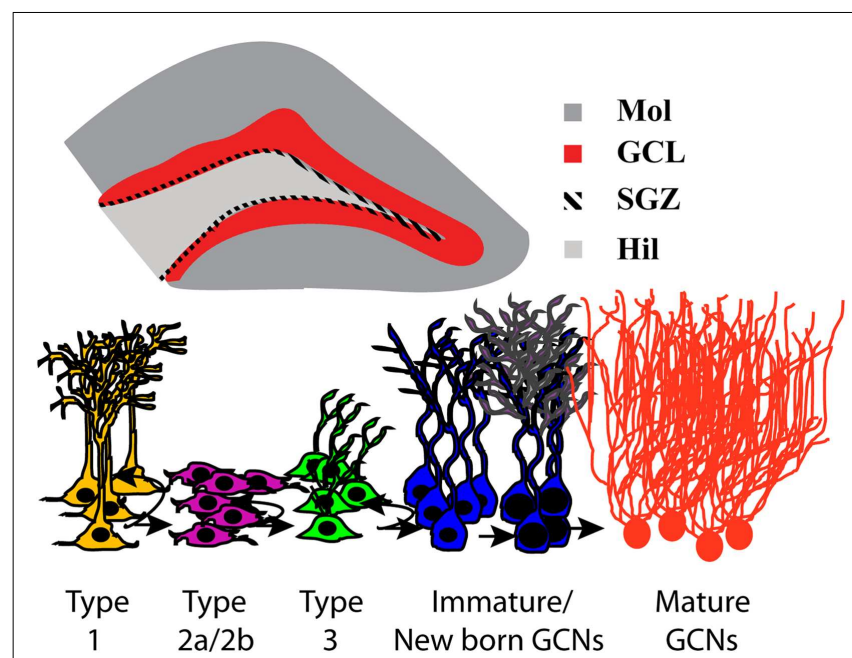

FIGURE 1 | Neurogenesis in the subgranular zone of the hippocampus. Schematic representation of the coronal view of the hippocampus region; magnification of the $D G$ region in a coronal view $-3.6 \mathrm{~mm}$ from bregma indicating the subregions of the $D G$ and highlighting the neurogenic region; GCL in red and SGZ as the hatched area. DG, dentate gyrus; GCL, granule cell layer; Mol, molecular layer; SGZ, subgranular zone; Hil, hilus. Stages of adult hippocampal neurogenesis are indicated below the schematic of the coronal view of the hippocampus. In the DG, type 1 putative stem-like cells are slowly dividing and rarely label with the commonly used exogenous mitotic marker 5-bromo-2'-deoxyuridine (BrdU) but can be identified via morphology and staining for nestin/GFAP/Sox2. BrdU will label rapidly dividing type 2 and some type 3 cells. Type 3 cells mature and differentiate into immature granule cell neurons and migrate a short distance into the granule cell layer to become granule cell neurons and integrate into the hippocampal circuitry.

glucocorticoid signaling (Vendruscolo et al., 2012), increased sensitivity to NMDA-mediated function (Becker et al., 1998; Gonzalez et al., 2001), and significant reductions in the rate of DG neurogenesis (Nixon and Crews, 2002; Richardson et al., 2009; Hansson et al., 2010) in a preclinical models of alcohol addiction and dependence. These data suggest that the normalization of alcoholimpaired DG neurogenesis during withdrawal may help reverse altered hippocampal neuroplasticity during protracted abstinence and thus may help reduce the vulnerability to relapse and aid recovery.

\section{ANIMAL MODELS OF CHRONIC ALCOHOL EXPOSURE AND ALCOHOL DEPENDENCE}

There are several in vitro and in vivo preclinical model systems that represents various stages of alcohol intoxication, addiction, and dependence. Three models are highlighted in this review; in vitro organotypic hippocampal cell culture model, intragastric intubation model, and chronic ethanol vapor induced dependence (CEID) model. The incorporation of these models has allowed us to determine the toxic and neuromodulatory effects of ethanol in specific brain regions and reward systems. The in vitro organotypic hippocampal cell culture model is commonly used to study hippocampal excitotoxicity associated with alcoholism. The in vitro model harbors critical hippocampal heterogeneity that is necessary for neuron-neuron and neuron-glia interactions to occur, thus maintaining the structural and functional integrity of

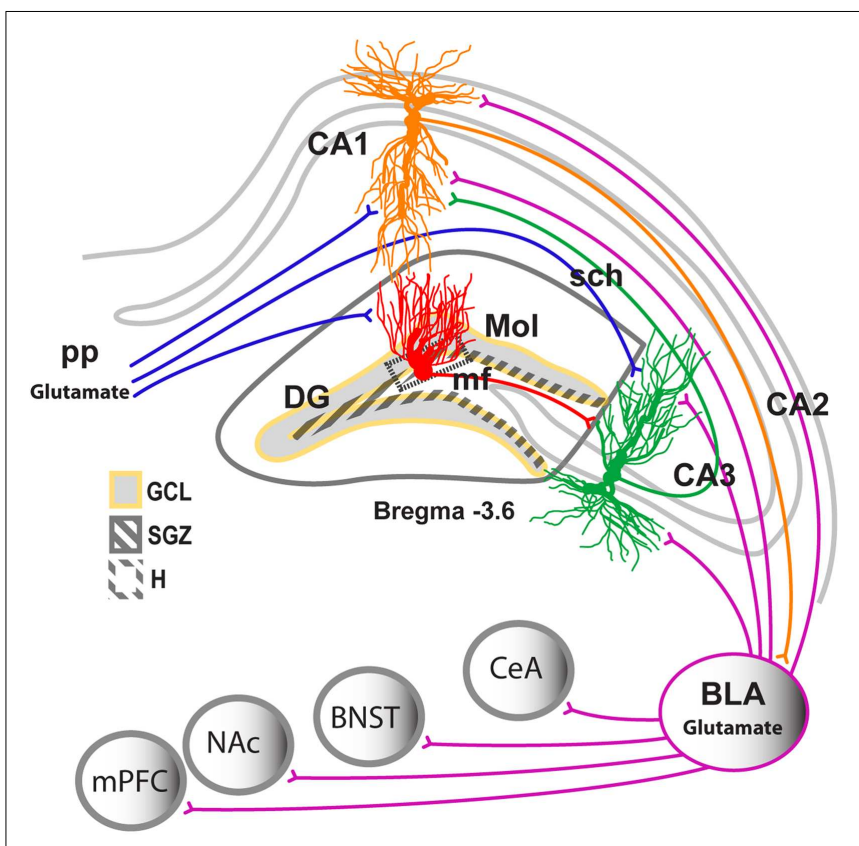

FIGURE 2 | Neuronal projections in the hippocampus. Schematic representation of the coronal view of the hippocampus region indicating the subregions of the hippocampus and their location within the hippocampus. CA, cornu ammonis; Trisynaptic circuitry in the hippocampus is indicated with axons from the entorhinal cortex projecting unidirectionally to the apical dendrites of the hippocampal DG, CA1, and CA3 neurons (perforant path projection). DG neurons project to the apical dendrites of the CA3 pyramidal neurons (mossy fiber projection). CA3 neurons project to the apical dendrites of the CA1 neurons (Schaffer collateral projection). The CA1 neurons have bidirectional projections to and from the BLA. The BLA also sends projections to the medial prefrontal cortex (mPFC), nucleus accumbens (NAc), bed nucleus of the stria terminalis (BNST), and central nucleus of the amygdala.

hippocampal circuitry and pharmacology (Gutierrez and Heinemann, 1999; Martens and Wree, 2001). Notably, the in vitro model has been extensively used to study the effects of chronic ethanol and withdrawal from ethanol on hippocampal neurotoxicity and excitotoxicity (Gibson et al., 2003; Prendergast et al., 2004; Wilkins et al., 2006). Studies indicate that ethanol excitotoxicity is dependent on the concentration of ethanol and duration of withdrawal after ethanol exposure. The intragastric intubation model has been widely used to study hippocampal neurotoxicity associated with alcoholism. This model produces observable signs of prodromal detoxification and physiological dependence (Majchrowicz, 1975), and these extreme signs of ethanol intoxication and dependence have been correlated with reduced neuroplasticity and enhanced neurodegeneration (Nixon and Crews, 2002; Crews and Nixon, 2009).

The CEID model of alcohol dependence links chronic ethanol exposure regimens with self-administration procedures. This model is based on the idea that dependence and the experience of withdrawal during dependence drive excessive drinking during withdrawal through altered motivational processes (e.g., negative reinforcement; O'Dell et al., 2004; Lopez and Becker, 2005; Gehlert et al., 2007; Griffin et al., 2009). The CEID model has several advantages compared with the intragastric intubation model of 
alcohol dependence because it causes increases in ethanol selfadministration and enhanced responsiveness to environmental stimuli that lead to excessive drinking in humans (Valdez et al., 2002; O'Dell et al., 2004). Importantly, CEID produces relatively high blood alcohol levels (BALs) during a short period of time, making this approach advantageous for studying the somatic aspects, motivational aspects, and neurobiological consequences of alcohol dependence (Macey et al., 1996; Liu and Weiss, 2002, 2003; Moore et al., 2004; Budygin et al., 2007; Miki et al., 2008; Gilpin et al., 2009; Richardson et al., 2009; Zahr et al., 2009). Altogether, investigating the neurobiological effects of chronic ethanol in CEID models has helped identify other vulnerability factors that contribute to the pathology of alcoholism in humans (Macey et al., 1996; Liu and Weiss, 2002, 2003; Moore et al., 2004; Budygin et al., 2007; Miki et al., 2008; Gilpin et al., 2009; Richardson et al., 2009; Zahr et al., 2009; Hansson et al., 2010).

\section{ALCOHOL AND THE MORPHOLOGY AND PLASTICITY OF THE HIPPOCAMPUS}

The hippocampus is involved in ethanol reward and relapse to ethanol seeking (Koob and Volkow, 2010; Zarrindast et al., 2010), suggesting that the hippocampus contributes to several aspects of alcohol dependence and can be implicated in the phenomena linked to alcohol use disorders. For example, alcohol dependence is linked to decreased hippocampus volume (Sullivan et al., 1995; Beresford et al., 2006), altered hippocampal morphology (Bengochea and Gonzalo, 1990; Durazzo et al., 2011), and deficits in hippocampus-dependent learning and memory (Brandt et al., 1983; Glenn and Parsons, 1991; Sullivan et al., 2000a,b, 2002). Alcohol exposure also alters the functional plasticity of hippocampal neurons. For instance, acute ethanol in hippocampal slices decreases hippocampal synaptic activity [i.e., decreases NMDA and $\alpha$-amino-3-hydroxy-5-methyl-4-isoxazolepropionic acid (AMPA) receptor-mediated currents and increases $\gamma$-aminobutyric acid-A $\left(\mathrm{GABA}_{\mathrm{A}}\right)$ receptor-mediated currents] and decreases hippocampal (CA1 and DG) long-term potentiation (LTP; Lovinger et al., 1989; Blitzer et al., 1990; Wayner et al., 1997; Weiner et al., 1999; Wright et al., 2003; Izumi et al., 2005; Fujii et al., 2008). Notably, chronic ethanol exposure also impairs hippocampal CA1 LTP through a presynaptic LTP mechanism (Durand and Carlen, 1984; Roberto et al., 2002) and produces tolerance to acute ethanol-mediated decreases in hippocampal LTP (Fujii et al., 2008), suggesting reorganization of hippocampal networking after chronic ethanol exposure. Furthermore, chronic ethanol exposure oppositely affects hippocampal synaptic activity compared with acute ethanol (increases in NMDA and decreases in $\mathrm{GABA}_{\mathrm{A}}$ receptor-mediated activity) and produces tolerance to acute ethanol-mediated impairment of NMDA activity and hippocampal-dependent behaviors (Sanna et al., 1993; Wu et al., 1993; Nelson et al., 2005; Sheela Rani and Ticku, 2006; Fujii et al., 2008). These findings indicate that the cellular mechanisms that maintain hippocampal plasticity are compensated in chronic ethanol-exposed animals. These maladaptive changes could contribute to the impairment of hippocampus-dependent behaviors in alcohol-dependent animals (Lukoyanov et al., 1999; Cippitelli et al., 2010; George et al., 2012). Chronic ethanol exposure produces dendritic retraction of CA1 pyramidal neurons (McMullen et al., 1984), suggesting concomitant structural reorganization of hippocampal neurons compared with functional changes in hippocampal circuitry. Recent evidence demonstrated that ethanol exposure altered a new form of hippocampal plasticity, such as DG neurogenesis (reviewed in (Nixon, 2006; Mandyam and Koob, 2012). Ethanol exposure (i.e., intragastric intubation, two-bottle choice, ethanol liquid diet, and CEID) altered every stage of DG neurogenesis, including the proliferation, differentiation, maturation, and survival of neural stem cells (Figure 1). These effects varied by the dose, duration, and pattern of ethanol exposure and timing of ethanol exposure before labeling the neural progenitors (Nixon and Crews, 2002; Crews et al., 2004; Rice et al., 2004; He et al., 2005; Ieraci and Herrera, 2007; Richardson et al., 2009; Taffe et al., 2010; Contet et al., 2013). Therefore, the inhibitory effect of ethanol on the regenerative capacity of the adult hippocampus is now being considered a precursor for ethanol-induced neurodegeneration in the hippocampus (Nixon, 2006).

\section{ALCOHOL EXPOSURE PRODUCES NEUROTOXICITY AND EXCITOTOXICITY IN THE HIPPOCAMPUS}

Using the in vitro organotypic hippocampal cell culture model, it has been demonstrated that hippocampal CA1 excitotoxicity is evident after withdrawal from chronic ethanol exposure and not during ethanol exposure (Mulholland et al., 2003; Prendergast et al., 2004; Wilkins et al., 2006). Withdrawal-associated effects have been shown to be due to the release of excessive glutamate and polyamines and corresponding activation of NMDA-type receptors in the hippocampal region (Gibson et al., 2003). Importantly, ethanol studies that used the in vitro model indicate the importance of the glutamatergic system as a final common pathway mediating neurotoxicity and excitotoxicity. There are also in vivo studies that support the involvement of the glutamatergic system in ethanol-induced hippocampal neurotoxicity in chronic ethanol-exposed animals (Claus et al., 1982; Keller et al., 1983; Wilce et al., 1993; Snell et al., 1996; Wirkner et al., 1999). For example, glutamate release is increased in the hippocampus during ethanol withdrawal (Claus et al., 1982; Keller et al., 1983), and changes in glutamate levels are associated with enhanced polyamine levels in combination with an increased number of functional NMDA receptors (Davidson et al., 1993, 1995). These results suggest that increased glutamate levels may induce ethanol withdrawal hyperexcitability and lead to increased susceptibility to hippocampal excitotoxicity (Hoffman, 2003).

\section{WITHDRAWAL AND PROTRACTED ABSTINENCE FROM ALCOHOL AND DG NEUROGENESIS}

Very few studies have explored how forced withdrawal from drug exposure alters DG neurogenesis (Nixon and Crews, 2004; Nixon et al., 2008; Noonan et al., 2008; Barr et al., 2010; Hansson et al., 2010; Taffe et al., 2010; Garcia-Fuster et al., 2011; Deschaux et al., 2012; Recinto et al., 2012). Withdrawal from ethanol exposure in the intragastric intubation and CEID paradigms enhanced cell proliferation in the hippocampus (Nixon and Crews, 2004; Hansson et al., 2010), resulting in initial microglial proliferation (Nixon et al., 2008) followed by the production of immature neurons and eventual neurogenesis (Nixon and Crews, 2004). Aberrant neurogenesis during abstinence is thought to be attributable to 
central nervous system hyperexcitability associated with ethanol withdrawal symptomatology, such as whole-body tremors that result from the termination of ethanol exposure. However, the cellular mechanisms regulating ethanol withdrawal-induced aberrant neurogenesis in the DG have not been identified, and future mechanistic studies are needed to address the contribution of aberrant DG neurogenesis to brain changes associated with alcohol dependence.

\section{WITHDRAWAL AND PROTRACTED ABSTINENCE FROM ALCOHOL AND EPILEPTOGENESIS AND NEUROADAPTATIONS IN THE HIPPOCAMPUS}

As discussed earlier, both in vitro and in vivo evidence suggests that glutamatergic neurotransmission is a critical mediator of the experience-dependent synaptic plasticity that may underlie alcohol dependence. It is hypothesized that a hyperglutamatergic state in the basolateral amygdala (BLA) resulting from termination of ethanol exposure may be regulated by a variety of neuroadaptations in the extended amygdala. These alterations may regulate the plasticity in the hippocampus to produce the withdrawal hyperexcitability associated with dependence (Hoffman and Tabakoff, 1994; Tsai et al., 1995; Nixon and Crews, 2004; McCool et al., 2010; Prior and Galduroz, 2011). For example, withdrawal from ethanol, especially the termination of CEID, produces withdrawal symptomatology, manifested as increased acoustic startle reactivity and tremor activity that peaks $12-24 \mathrm{~h}$ post-withdrawal (Macey et al., 1996). These somatic symptoms of ethanol withdrawal seem to have an immediate effect on hippocampal plasticity. Withdrawal from CEID produces a rebound effect on the proliferation of neural progenitors that occurs $72 \mathrm{~h}$ after the termination of CEID. These cells propagate into aberrant immature GCNs during protracted abstinence (Hansson et al., 2010). Notably, pilocarpineinduced status epilepticus also produces abnormal proliferation of neural progenitors in the DG that is evident $72 \mathrm{~h}$ after seizure activity (Parent et al., 1997). This is a timeframe comparable to ethanol withdrawal-induced alterations. In addition to the alterations in DG neural progenitors, both epileptic activity and withdrawal from CEID have other common cellular and molecular neuroadaptations in the hippocampus. Particularly interesting is the increases in NMDA receptor 2B (NR2B) subunit expression in the hippocampus during CEID (Pian et al., 2010) and CRF levels in the hippocampus during withdrawal (Criado et al., 2011). These changes parallel the increased NR2B subunit and CRF expression in the hippocampus during epileptogenesis (Smith et al., 1997; Frasca et al., 2011). Altogether, it appears that the hyperactivity stemming from the neurocircuitry underlying ethanol withdrawal-induced kindling-like behaviors causes a hyperglutamatergic state and produces hippocampal excitotoxicity, which may be decisive factors for the maintenance of long-term dependence (Baram et al., 1992; Smith et al., 1997; Wilkins et al., 2006; Frasca et al., 2011; Prior and Galduroz, 2011).

\section{WITHDRAWAL AND PROTRACTED ABSTINENCE FROM ALCOHOL ALTER HPA AXIS AND GLUCOCORTICOID RECEPTOR SIGNALING}

Animals made dependent by CEID or liquid diet procedures have attenuated (opposing) basal stress hormone levels (adrenocorticotropic hormone and corticosterone) compared with non-dependent drinking animals (enhanced stress hormone levels). It has been demonstrated that the blunted stress response is a consequence of chronic ethanol exposure (Zorrilla et al., 2001; Richardson et al., 2008). Importantly, the findings from animal studies are consistent with clinical studies that link maladaptive HPA axis function with alcoholism, including a reduced ability to cope with stress and negative correlations between cortisol and craving and relapse in alcoholics (Lovallo et al., 2000; O'Malley et al., 2002). Although the precise mechanism underlying the attenuated stress response is unknown, several studies have implicated activation of CRF systems in the extended amygdala in the dysregulation of the stress system associated with dependence (Wand, 2005; Koob, 2008). Furthermore, enhanced glucocorticoid receptor (GR) levels in the extended amygdala during protracted abstinence have been demonstrated in dependent animals. Such associated changes in the GR system could play a mechanistic role in the sensitivity to stress/reward and relapse associated with alcohol dependence (Vendruscolo et al., 2012). However, the functional significance of altered GR system in mediating blunted stress responses in alcohol dependence is unknown.

\section{RELATIONSHIP BETWEEN ETHANOL-INDUCED NEUROADAPTIVE CHANGES IN THE AMYGDALA AND ABERRANT DG NEUROGENESIS}

The aberrant stimulation of cell proliferation in the DG during withdrawal from chronic ethanol exposure has been demonstrated in the in vitro organotypic hippocampal cell culture model (Wilkins et al., 2006), intragastric intubation model (Nixon and Crews, 2004; Nixon et al., 2008), and CEID model (Hansson et al., 2010). Further mechanistic experiments that used the intragastric intubation model demonstrated that observable withdrawal signs correlated with increases in cell proliferation. However, rescuing the observable withdrawal symptoms with diazepam did not normalize the cell proliferation effects (Nixon and Crews, 2004). This suggests that withdrawal-induced enhanced proliferation is not secondary to the physiological withdrawal experienced by the animal but may be related to the neuroadaptations linked to the negative affect symptoms associated with alcohol dependence.

Possible mechanisms underlying ethanol withdrawal-induced aberrant DG cell proliferation and neurogenesis can be postulated based on the available literature. For example, the increased synthesis of hippocampal CRF during withdrawal (Criado et al., 2011) might promote excitatory activity and lead to BLA hyperexcitability, which in turn may increase the level of CRF at critical hippocampal synapses (Figure 2). Such a mechanism would further enhance excitability in a positive-feedback manner in the hippocampus during ethanol withdrawal (Baram and Hatalski, 1998; Hollrigel et al., 1998; Chen et al., 2004). Increased CRF synthesis in the hippocampus could be due to decreased hippocampal inhibitory GABA activity seen during ethanol withdrawal (Frye et al., 1983; Fujii et al., 2008). The excitatory effect of CRF on DG neurons in the hippocampus may occur indirectly through CRFinduced activation of excitatory inputs into the hippocampus to cause DG hyperexcitability (Hollrigel et al., 1998). Epileptogenic studies suggest that excitatory glutamatergic projections from the 
BLA are implicated in DG excitotoxicity and hyperexcitability (Baram et al., 1992; Freund and Buzsaki, 1996; Smith et al., 1997; Hollrigel et al., 1998; Yan et al., 1998; Wang et al., 2000). Notably, most of the projection neurons from the BLA to the hippocampus are glutamatergic and express $\mathrm{CRF}_{1}$ receptors. Specific knockdown of $\mathrm{CRF}_{1}$ in BLA glutamatergic neurons produces anxiolytic-like effects (Refojo et al., 2011). Furthermore, the CRF system in the BLA is hypothesized to be recruited by chronic kindling cycles of ethanol exposure/withdrawal (Baram et al., 1992; Rimondini et al., 2003; Breese et al., 2004; Knapp et al., 2004; Overstreet et al., 2004; O'Dell et al., 2004) and mediate the motivating, negative affective symptoms of both acute and protracted abstinence from ethanol. Protracted abstinence from CEID enhances BLA CRF 1 levels (Sommer et al., 2008), suggesting that BLA sensitivity to CRF increases in a kindling-like fashion during withdrawal (Sajdyk et al., 1999; Sajdyk and Gehlert, 2000; Rainnie et al., 2004). Recent functional studies demonstrated that DG neurogenesis is regulated by BLA neuronal activity (Kirby et al., 2012), and a kindling procedure specifically in the BLA produced aberrant DG neurogenesis, which resulted from the altered expression of cell differentiation factors in the DG neurogenic niche (Fournier et al., 2010). Therefore, increases in CRF in the extended amygdala could produce secondary effects on DG neurogenesis via the BLA. These alterations could be hypothesized to be regulated by corticosterone levels (Makino et al., 1994).

A related mechanism for ethanol withdrawal-induced increases in cell proliferation and DG neurogenesis could be ethanol withdrawal-induced blunting of corticosterone levels (Richardson et al., 2008) and corresponding increases in GR levels in the extended amygdala (Vendruscolo et al., 2012). The reduced levels of corticosterone could enhance DG proliferation and neurogenesis to assist with the hippocampal negative feedback regulation of HPA axis activity (Jankord and Herman, 2008; Snyder et al., 2011). Furthermore, it has been demonstrated that withdrawal is associated with upregulation of NMDA receptors, specifically in

\section{REFERENCES}

Abraham, I. M., Harkany, T., Horvath, K. M., and Luiten, P. G. (2001). Action of glucocorticoids on survival of nerve cells: promoting neurodegeneration or neuroprotection? J. Neuroendocrinol. 13, 749-760. doi:10.1046/j.13652826.2001.00705.x

Abrous, D. N., Koehl, M., and Le Moal, M. (2005). Adult neurogenesis: from precursors to network and physiology. Physiol. Rev. 85, 523-569. doi:10.1152/physrev.00055.2003

Aimone, J. B., Deng, W., and Gage, F. H. (2011). Resolving new memories: a critical look at the dentate gyrus, adult neurogenesis, and pattern separation. Neuron 70, 589-596. doi:10.1016/j.neuron.2011.05.010

Aimone, J. B., Wiles, J., and Gage, F. H. (2006). Potential role for adult neurogenesis in the encoding of time in new memories. Nat. Neurosci. 9, 723-727. doi:10.1038/nn 1707
Bakker, A., Kirwan, C. B., Miller, M., and Stark, C. E. (2008). Pattern separation in the human hippocampal CA3 and dentate gyrus. Science 319, 1640-1642. doi:10.1126/science.1152882

Baram, T. Z., and Hatalski, C. G. (1998). Neuropeptide-mediated excitability: a key triggering mechanism for seizure generation in the developing brain. Trends Neurosci. 21, 471-476. doi:10.1016/S0166-2236(98)012752

Baram, T. Z., Hirsch, E., Snead, O. C. 3rd, and Schultz, L. (1992). Corticotropin-releasing hormone-induced seizures in infant rats originate in the amygdala. Ann. Neurol. 31, 488-494. doi:10.1002/ana.410310505

Barr, J. L., Renner, K. J., and Forster, G. L. (2010). Withdrawal from chronic amphetamine produces persistent anxiety-like behavior but temporally-limited reductions in

the hippocampus (Hoffman, 2003), which is perhaps secondary to glucocorticoid-dependent excess release of endogenous glutamate and polyamines in the hippocampus and extended amygdala (Abraham et al., 2001; Gibson et al., 2003). Although NMDA receptor activation has been shown to reduce cell proliferation in a normal state (Cameron et al., 1995), this effect is reversed during cytotoxicity (e.g., ethanol withdrawal; Wilkins et al., 2006) and could be attributable to the altered expression of NMDA receptor subunits in chronic ethanol-exposed animals compared with ethanol-naive animals (Prendergast and Mulholland, 2012; Ren et al., 2013). Altogether, specific corticosteroid-mediated neuroadaptations in the CRF system in the extended amygdala following ethanol withdrawal could produce a hyperglutamatergic state in the hippocampus, which may regulate aberrant neurogenesis in the DG. The resulting pathological plasticity could facilitate the recruitment of new GCNs into emotional memory circuits and therefore contribute to the pathology of alcohol dependence (Farioli-Vecchioli et al., 2009; Fournier et al., 2013). Future studies should seek to understand the underlying mechanism of ethanol withdrawal-induced aberrant DG neurogenesis. Such studies may help determine whether hippocampal GCNs born during withdrawal perform improper functions to inhibit regeneration in the hippocampus (excitotoxicity) and aid with recruitment of new neurons into emotional memory circuitry (negative affect).

\section{ACKNOWLEDGMENTS}

Preparation of this review was supported by funds from the National Institute on Drug Abuse (DA022473). National Institute on Alcohol Abuse and Alcoholism (AA020098, AA006420), and the Alcoholic Beverage Medical Research Foundation. I would like to thank Dr. Leandro Vendruscolo for critically reading the manuscript and helpful discussions, Michael Arends for his editorial assistance and Janet Hightower for assistance with graphics. This is manuscript number 24035 from The Scripps Research Institute.

monoamines and neurogenesis in the adult rat dentate gyrus. $\mathrm{Neu}$ ropharmacology 59, 395-405. doi:10. 1016/j.neuropharm.2010.05.011

Becker, H. C., Veatch, L. M., and Diaz-Granados, J. L. (1998). Repeated ethanol withdrawal experience selectively alters sensitivity to different chemoconvulsant drugs in mice. Psychopharmacology (Berl.) 139, 145-153. doi:10.1007/s002130050699

Bengochea, O., and Gonzalo, L. M. (1990). Effect of chronic alcoholism on the human hippocampus. Histol. Histopathol. 5, 349-357.

Beresford, T. P., Arciniegas, D. B., Alfers, J., Clapp, L., Martin, B., Du, Y., et al. (2006). Hippocampus volume loss due to chronic heavy drinking. Alcohol. Clin. Exp. Res. 30, 1866-1870. doi:10.1111/j.15300277.2006.00223.x

Blitzer, R. D., Gil, O., and Landau, E. M. (1990). Long-term potentiation in rat hippocampus is inhibited by low concentrations of ethanol. Brain Res. 537, 203-208. doi:10.1016/00068993(90)90359-J

Brandt, J., Butters, N., Ryan, C., and Bayog, R. (1983). Cognitive loss and recovery in long-term alcohol abusers. Arch. Gen. Psychiatry 40, 435-442. doi:10.1001/archpsyc.1983.017900 40089012

Breese, G. R., Knapp, D. J., and Overstreet, D. H. (2004). Stress sensitization of ethanol withdrawal-induced reduction in social interaction: inhibition by CRF-1 and benzodiazepine receptor antagonists and a 5-HT1A-receptor agonist. $\mathrm{Neu}$ ropsychopharmacology 29, 470-482. doi:10.1038/sj.npp.1300419

Budygin, E. A., Oleson, E. B., Mathews, T. A., Lack, A. K., Diaz, M. R., McCool, B. A., et al. (2007). Effects of chronic alcohol exposure on dopamine uptake 
in rat nucleus accumbens and caudate putamen. Psychopharmacology (Berl.) 193, 495-501. doi:10.1007/s00213-007-0812-1

Cameron, H. A., and Gould, E. (1994). Adult neurogenesis is regulated by adrenal steroids in the dentate gyrus. Neuroscience 61, 203-209. doi:10.1016/0306-4522(94)90224-0

Cameron, H. A., McEwen, B. S., and Gould, E. (1995). Regulation of adult neurogenesis by excitatory input and NMDA receptor activation in the dentate gyrus. J. Neurosci. 15, 4687-4692.

Chen, Y., Bender, R. A., Brunson, K. L., Pomper, J. K., Grigoriadis, D. E., Wurst, W., et al. (2004). Modulation of dendritic differentiation by corticotropinreleasing factor in the developing hippocampus. Proc. Natl. Acad. Sci. U.S.A. 101, 15782-15787. doi:10.1073/pnas.0403975101

Cippitelli, A., Zook, M., Bell, L., Damadzic, R., Eskay, R. L., Schwandt, M., et al. (2010). Reversibility of object recognition but not spatial memory impairment following binge-like alcohol exposure in rats. Neurobiol. Learn. Mem. 94, 538-546. doi:10.1016/j.nlm

Clark, P. J., Bhattacharya, T. K., Miller, D. S., Kohman, R. A., DeYoung, E. K., and Rhodes, J. S. (2012). New neurons generated from running are broadly recruited into neuronal activation associated with three different hippocampusinvolved tasks. Hippocampus 22, 1860-1867. doi:10.1002/hipo.22020

Claus, D., Kim, J. S., Kornhuber, M. E., and Ahn, Y. S. (1982). Effect of ethanol on the neurotransmitters glutamate and GABA. Arch. Psychiatr. Nervenkr. 232, 183-189. doi:10.1007/BF00343699

Clelland, C. D., Choi, M., Romberg, C., Clemenson, G. D. Jr., Fragniere, A., Tyers, P., et al. (2009). A functional role for adult hippocampal neurogenesis in spatial pattern separation. Science 325, 210-213. doi:10.1126/science.1173215

Contet, C., Kim, A., Le, D., Iyengar, S. K., Kotzebue, R. W., Yuan, C. J., et al. (2013). mu-Opioid receptors mediate the effects of chronic ethanol binge drinking on the hippocampal neurogenic niche. Addict. Biol. doi:10.1111/adb.12040

Crews, F. T., and Nixon, K. (2009). Mechanisms of neurodegeneration and regeneration in alcoholism. Alcohol Alcohol. 44, 115-127. doi:10.1093/alcalc/agn079

Crews, F. T., Nixon, K., and Wilkie, M. E. (2004). Exercise reverses ethanol inhibition of neural stem cell proliferation. Alcohol 33, 63-71. doi:10. 1016/S0741-8329(04)00081-3

Criado, J. R., Liu, T., Ehlers, C. L., and Mathe, A. A. (2011). Prolonged chronic ethanol exposure alters neuropeptide $\mathrm{Y}$ and corticotropinreleasing factor levels in the brain of adult Wistar rats. Pharmacol. Biochem. Behav. 99, 104-111. doi:10.1016/j.pbb.2011.04.005

Curtis, M. A., Kam, M., Nannmark, U., Anderson, M. F., Axell, M. Z., Wikkelso, C., et al. (2007). Human neuroblasts migrate to the olfactory bulb via a lateral ventricular extension. Science 315, 1243-1249. doi:10.1126/science.1136281

Davidson, M., Shanley, B., and Wilce, P. (1995). Increased NMDA-induced excitability during ethanol withdrawal: a behavioural and histological study. Brain Res. 674, 91-96. doi:10.1016/0006-8993(94)01440-S

Davidson, M. D., Wilce, P., and Shanley, B. C. (1993). Increased sensitivity of the hippocampus in ethanol-dependent rats to toxic effect of N-methyl-D-aspartic acid in vivo. Brain Res. 606, 5-9. doi:10.1016/0006-8993(93)91562-7

Deisseroth, K., Singla, S., Toda, H., Monje, M., Palmer, T. D., and Malenka, R. C. (2004). Excitationneurogenesis coupling in adult neural stem/progenitor cells. Neuron 42, 535-552. doi:10.1016/S08966273(04)00266-1

Deschaux, O., Vendruscolo, L. F., Schlosburg, J. E., Diaz-Aguilar, L., Yuan, C. J., Sobieraj, J. C., et al. (2012). Hippocampal neurogenesis protects against cocaine-primed relapse. Addict. Biol. doi:10.1111/adb.12019

Durand, D., and Carlen, P. L. (1984). Impairment of long-term potentiation in rat hippocampus following chronic ethanol treatment. Brain Res. 308, 325-332. doi:10.1016/0006-8993(84)91072-2

Durazzo, T. C., Tosun, D., Buckley, S., Gazdzinski, S., Mon, A., Fryer, S. L., et al. (2011). Cortical thickness, surface area, and volume of the brain reward system in alcohol dependence: relationships to relapse and extended abstinence. Alcohol. Clin. Exp. Res. 35, 1187-1200. doi:10.1111/j.15300277.2011.01452.x

Eriksson, P. S., Perfilieva, E., BjorkEriksson, T., Alborn, A. M., Nordborg, C., Peterson, D. A., et al. (1998). Neurogenesis in the adult human hippocampus. Nat. Med. 4, 1313-1317. doi:10.1038/3305

Farioli-Vecchioli, S., Saraulli, D., Costanzi, M., Leonardi, L., Cina,
I., Micheli, L., et al. (2009). Impaired terminal differentiation of hippocampal granule neurons and defective contextual memory in PC3/Tis21 knockout mice. PLoS ONE 4:e8339. doi:10.1371/journal.pone.0008339

Feng, R., Rampon, C., Tang, Y. P., Shrom, D., Jin, J., Kyin, M., et al. (2001). Deficient neurogenesis in forebrain-specific presenilin1 knockout mice is associated with reduced clearance of hippocampal memory traces. Neuron 32, 911-926. doi:10.1016/S08966273(01)00523-2

Fournier, N. M., Andersen, D. R., Botterill, J. J., Sterner, E. Y., Lussier, A. L., Caruncho, H. J., et al. (2010). The effect of amygdala kindling on hippocampal neurogenesis coincides with decreased reelin and DISC1 expression in the adult dentate gyrus. Hippocampus 20, 659-671.

Fournier, N. M., Botterill, J. J., Marks, W. N., Guskjolen, A. J., and Kalynchuk, L. E. (2013). Impaired recruitment of seizure-generated neurons into functional memory networks of the adult dentate gyrus following long-term amygdala kindling. Exp. Neurol. 244, 96-104. doi:10.1016/j.expneurol.2012.11.031 Frasca, A., Aalbers, M., Frigerio, F., Fiordaliso, F., Salio, M., Gobbi, M., et al. (2011). Misplaced NMDA receptors in epileptogenesis contribute to excitotoxicity. Neurobiol. Dis. 43, 507-515. doi:10.1016/j.nbd.2011.04.024

Freund, T. F., and Buzsaki, G. (1996). Interneurons of the hippocampus. Hippocampus 6 347-470. doi:10.1002/(SICI)10981063(1996)6:4\&lt;347::AIDHIPO1\&gt;3.0.CO;2-I

Frye, G. D., McCown, T. J., and Breese, G. R. (1983). Differential sensitivity of ethanol withdrawal signs in the rat to gamma-aminobutyric acid (GABA)mimetics: blockade of audiogenic seizures but not forelimb tremors. J. Pharmacol. Exp. Ther. 226, 720-725.

Fujii, S., Yamazaki, Y., Sugihara, T., and Wakabayashi, I. (2008). Acute and chronic ethanol exposure differentially affect induction of hippocampal LTP. Brain Res. 1211 , 13-21. doi:10.1016/j.brainres.2008. 02.052

Garcia-Fuster, M. J., Flagel, S. B., Mahmood, S. T., Mayo, L. M., Thompson, R. C., Watson, S. J., et al. (2011). Decreased proliferation of adult hippocampal stem cells during cocaine withdrawal: possible role of the cell fate regulator
FADD. Neuropsychopharmacology 36, 2303-2317. doi:10.1038/npp. 2011.119

Gehlert, D. R., Cippitelli, A., Thorsell, A., Le, A. D., Hipskind, P. A., Hamdouchi, C., et al. (2007). 3-(4-Chloro-2morpholin-4-yl-thiazol-5-yl)-8-(1ethylpropyl)-2,6-dimethyl-imidazo [1,2-b]pyridazine: a novel brainpenetrant, orally available corticotropin-releasing factor receptor 1 antagonist with efficacy in animal models of alcoholism. J. Neurosci. 27, 2718-2726. doi:10.1523/JNEUROSCI.498506.2007

George, O., Sanders, C., Freiling, J., Grigoryan, E., Vu, S., Allen, C. D., et al. (2012). Recruitment of medial prefrontal cortex neurons during alcohol withdrawal predicts cognitive impairment and excessive alcohol drinking. Proc. Natl. Acad. Sci. U.S.A. 109, 18156-18161. doi:10.1073/pnas.1116523109

Gibson, D. A., Harris, B. R., Prendergast, M. A., Hart, S. R., Blanchard, J. A. II, Holley, R. C., et al. (2003). Polyamines contribute to ethanol withdrawal-induced neurotoxicity in rat hippocampal slice cultures through interactions with the NMDA receptor. Alcohol. Clin. Exp. Res. 27, 1099-1106. doi:10.1097/01.ALC.0000075824. 10502.DD

Gilpin, N. W., Smith, A. D., Cole, M., Weiss, F., Koob, G. F., and Richardson, H. N. (2009). Operant behavior and alcohol levels in blood and brain of alcohol-dependent rats. Alcohol. Clin. Exp. Res. 33, 2113-2123. doi:10.1111/j.15300277.2009.01051.x

Glenn, S. W., and Parsons, O. A. (1991). Impaired efficiency in female alcoholics' neuropsychological performance. J. Clin. Exp. Neuropsychol. 13, 895-908. doi:10.1080/01688639108405106

Gonzalez, L. P., Veatch, L. M., Ticku, M. K., and Becker, H. C. (2001). Alcohol withdrawal kindling: mechanisms and implications for treatment. Alcohol. Clin. Exp. Res. 25, 197S-201S. doi:10.1111/j.15300277.2001.tb02396.x

Gould, E., Beylin, A., Tanapat, P., Reeves, A., and Shors, T. J. (1999). Learning enhances adult neurogenesis in the hippocampal formation. Nat. Neurosci. 2, 260-265. doi:10.1038/6365

Griffin, W. C. 3rd, Lopez, M. F., and Becker, H. C. (2009). Intensity and duration of chronic ethanol exposure is critical for subsequent escalation of voluntary ethanol drinking 
in mice. Alcohol. Clin. Exp. Res. 33, 1893-1900. doi:10.1111/j.15300277.2009.01027.x

Gutierrez, R., and Heinemann, U. (1999). Synaptic reorganization in explanted cultures of rat hippocampus. Brain Res. 815, 304-316. doi:10. 1016/S0006-8993(98)01101-9

Hansson, A. C., Nixon, K., Rimondini, R., Damadzic, R., Sommer, W. H., Eskay, R., et al. (2010). Long-term suppression of forebrain neurogenesis and loss of neuronal progenitor cells following prolonged alcohol dependence in rats. Int. J. Neuropsychopharmacol. 13, 583-593. doi:10.1017/S1461145710000246

Hastings, N. B., Tanapat, P., and Gould, E. (2001). Neurogenesis in the adult mammalian brain. Clin. Neurosci. Res. 1, 175-182. doi:10.1016/S15662772(01)00003-2

He, J., Nixon, K., Shetty, A. K., and Crews, F. T. (2005). Chronic alcohol exposure reduces hippocampal neurogenesis and dendritic growth of newborn neurons. Eur. J. Neurosci. 21, 2711-2720. doi:10.1111/j.14609568.2005.04120.x

Hoffman, P. L. (2003). NMDA receptors in alcoholism. Int. Rev. Neurobiol. 56, 35-82. doi:10.1016/S00747742(03)56002-0

Hoffman, P. L., and Tabakoff, B. (1994). The role of the NMDA receptor in ethanol withdrawal. EXS 71, 61-70.

Hollrigel, G. S., Chen, K., Baram, T. Z., and Soltesz, I. (1998). The pro-convulsant actions of corticotropin-releasing hormone in the hippocampus of infant rats. Neuroscience 84, 71-79. doi:10. 1016/S0306-4522(97)00499-5

Ieraci, A., and Herrera, D. G. (2007). Single alcohol exposure in early life damages hippocampal stem/progenitor cells and reduces adult neurogenesis. Neurobiol. Dis. 26, 597-605. doi:10.1016/j.nbd.2007.02.011

Izumi, Y., Nagashima, K., Murayama, K., and Zorumski, C. F. (2005). Acute effects of ethanol on hippocampal long-term potentiation and long-term depression are mediated by different mechanisms. Neuroscience 136, 509-517. doi:10.1016/j.neuroscience.2005. 08.002

Jankord, R., and Herman, J. P. (2008). Limbic regulation of hypothalamopituitary-adrenocortical function during acute and chronic stress. Ann. N. Y. Acad. Sci. 1148, 64-73. doi:10.1196/annals.1410.012

Kaplan, M. S., and Hinds, J. W. (1977). Neurogenesis in the adult rat: electron microscopic analysis of light radioautographs. Science 197, 1092-1094. doi:10.1126/science.887941

Keller, E., Cummins, J. T., and von Hungen, K. (1983). Regional effects of ethanol on glutamate levels, uptake and release in slice and synaptosome preparations from rat brain. Subst. Alcohol Actions Misuse 4, 383-392.

Kempermann, G., Jessberger, S., Steiner, B., and Kronenberg, G. (2004). Milestones of neuronal development in the adult hippocampus. Trends Neurosci. 27, 447-452. doi:10.1016/j.tins.2004.05.013

Kim, W. R., Christian, K., Ming, G. L., and Song, H. (2012). Timedependent involvement of adultborn dentate granule cells in behavior. Behav. Brain Res. 227, 470-479. doi:10.1016/j.bbr.2011.07.012

Kirby, E. D., Friedman, A. R., Covarrubias, D., Ying, C., Sun, W. G., Goosens, K. A., et al. (2012). Basolateral amygdala regulation of adult hippocampal neurogenesis and fearrelated activation of newborn neurons. Mol. Psychiatry 17, 527-536. doi:10.1038/mp.2011.71

Knapp, D. J., Overstreet, D. H., Moy, S. S., and Breese, G. R. (2004). SB242084, flumazenil, and CRA1000 block ethanol withdrawal-induced anxiety in rats. Alcohol 32, 101-111. doi:10.1016/j.alcohol.2003.08.007

Koob, G. F. (2008). A role for brain stress systems in addiction. Neuron 59, 11-34. doi:10.1016/j.neuron.2008.06.012

Koob, G. F., and Volkow, N. D. (2010). Neurocircuitry of addiction. Neuropsychopharmacology 35, 217-238. doi:10.1038/npp.2009.110

Lacefield, C. O., Itskov, V., Reardon, T., Hen, R., and Gordon, J. A. (2012). Effects of adultgenerated granule cells on coordinated network activity in the dentate gyrus. Hippocampus 22, 106-116. doi:10.1002/hipo.20860

Liu, X., and Weiss, F. (2002). Additive effect of stress and drug cues on reinstatement of ethanol seeking: exacerbation by history of dependence and role of concurrent activation of corticotropin-releasing factor and opioid mechanisms. J. Neurosci. 22, 7856-7861.

Liu, X., and Weiss, F. (2003). Stimulus conditioned to foot-shock stress reinstates alcohol-seeking behavior in an animal model of relapse. Psychopharmacology (Berl.) 168, 184-191. doi:10.1007/s00213-002-1267-z

Lopez, M. F., and Becker, H. C. (2005). Effect of pattern and number of chronic ethanol exposures on subsequent voluntary ethanol intake in C57BL/6J mice. Psychopharmacology (Berl.) 181, 688-696. doi:10.1007/s00213-005-0026-3

Lovallo, W. R., Dickensheets, S. L., Myers, D. A., Thomas, T. L., and Nixon, S. J. (2000). Blunted stress cortisol response in abstinent alcoholic and polysubstanceabusing men. Alcohol. Clin. Exp. Res. 24, 651-658. doi:10.1111/j.15300277.2000.tb02036.x

Lovinger, D. M., White, G., and Weight, F. F. (1989). Ethanol inhibits NMDA-activated ion current in hippocampal neurons. Science 243, 1721-1724. doi:10.1126/science. 2467382

Lukoyanov, N. V., Madeira, M. D., and Paula-Barbosa, M. M. (1999). Behavioral and neuroanatomical consequences of chronic ethanol intake and withdrawal. Physiol. Behav. 66, 337-346. doi:10.1016/S0031-9384 (98)00301-1

Macey, D. J., Schulteis, G., Heinrichs, S. C., and Koob, G. F. (1996). Time-dependent quantifiable withdrawal from ethanol in the rat: effect of method of dependence induction. Alcohol 13, 163-170. doi:10.1016/0741-8329(95)02030-6

Majchrowicz, E. (1975). Induction of physical dependence upon ethanol and the associated behavioral changes in rats. Psychopharmacologia 43, 245-254. doi:10.1007/BF00429258

Makino, S., Gold, P. W., and Schulkin, J. (1994). Corticosterone effects on corticotropin-releasing hormone mRNA in the central nucleus of the amygdala and the parvocellular region of the paraventricular nucleus of the hypothalamus. Brain Res. 640, 105-112. doi:10.1016/0006-8993(94)91862-7

Mandyam, C. D., and Koob, G. F. (2012). The addicted brain craves new neurons: putative role for adult-born progenitors in promoting recovery. Trends Neurosci. 35, 250-260. doi:10.1016/j.tins.2011.12.005

Martens, U., and Wree, A. (2001). Distribution of $[3 \mathrm{H}] \mathrm{MK}-801,[3 \mathrm{H}] \mathrm{AMPA}$ and $[3 \mathrm{H}]$ Kainate binding sites in rat hippocampal long-term slice cultures isolated from external afferents. Anat. Embryol. 203, 491-500. doi:10.1007/s004290100174

McCool, B. A., Christian, D. T., Diaz M. R., and Lack, A. K. (2010). Glutamate plasticity in the drunken amygdala: the making of an anxious synapse. Int. Rev. Neurobiol. 91, 205-233. doi:10.1016/S00747742(10)91007-6
McHugh, T. J., Jones, M. W., Quinn, J. J., Balthasar, N., Coppari, R., Elmquist, J. K., et al. (2007). Dentate gyrus NMDA receptors mediate rapid pattern separation in the hippocampal network. Science 317, 94-99. doi:10.1126/science.1140263

McMullen, P. A., Saint-Cyr, J. A., and Carlen, P. L. (1984). Morphological alterations in rat CA1 hippocampal pyramidal cell dendrites resulting from chronic ethanol consumption and withdrawal. J. Comp. Neurol. 225, 111-118. doi:10.1002/cne.902250112

Miki, T., Kuma, H., Yokoyama, T., Sumitani, K., Matsumoto, Y., Kusaka, T., et al. (2008). Early postnatal ethanol exposure induces fluctuation in the expression of BDNF mRNA in the developing rat hippocampus. Acta Neurobiol. Exp. (Wars) 68, 484-493.

Mirescu, C., and Gould, E. (2006). Stress and adult neurogenesis. Hippocampus 16, 233-238. doi:10.1002/hipo.20155

Moore, D. B., Madorsky, I., Paiva, M., and Barrow Heaton, M. (2004). Ethanol exposure alters neurotrophin receptor expression in the rat central nervous system: effects of neonatal exposure. J. Neurobiol. 60, 114-126. doi:10.1002/neu.20010

Mulholland, P. J., Harris, B. R., Wilkins, L. H., Self, R. L., Blanchard, J. A., Holley, R. C., et al. (2003). Opposing effects of ethanol and nicotine on hippocampal calbindinD28k expression. Alcohol 31, 1-10. doi:10.1016/j.alcohol.2003.09.001

Nelson, T. E., Ur, C. L., and Gruol, D. L. (2005). Chronic intermittent ethanol exposure enhances NMDA-receptor-mediated synaptic responses and NMDA receptor expression in hippocampal CA1 region. Brain Res. 1048, 69-79. doi:10.1016/j.brainres.2005.04.041

Nixon, K. (2006). Alcohol and adult neurogenesis: roles in neurodegeneration and recovery in chronic alcoholism. Hippocampus 16, 287-295. doi:10.1002/hipo.20162

Nixon, K., and Crews, F. T. (2002). Binge ethanol exposure decreases neurogenesis in adult rat hippocampus. J. Neurochem. 83, 1087-1093. doi:10.1046/j.14714159.2002.01214.x

Nixon, K., and Crews, F. T. (2004). Temporally specific burst in cell proliferation increases hippocampal neurogenesis in protracted abstinence from alcohol. J. Neurosci. 24, 9714-9722. doi:10.1523/JNEUROSCI.306304.2004 
Nixon, K., Kim, D. H., Potts, E. N., He, J., and Crews, F. T. (2008). Distinct cell proliferation events during abstinence after alcohol dependence: microglia proliferation precedes neurogenesis. Neurobiol. Dis. 31, 218-229. doi:10.1016/j.nbd.2008.04.009

Noonan, M. A., Choi, K. H., Self, D. W., and Eisch, A. J. (2008). Withdrawal from cocaine self-administration normalizes deficits in proliferation and enhances maturity of adult-generated hippocampal neurons. J. Neurosci. 28, 2516-2526. doi:10.1523/JNEUROSCI.466107.2008

O’Dell, L. E., Roberts, A. J., Smith, R. T., and Koob, G. F. (2004). Enhanced alcohol self-administration after intermittent versus continuous alcohol vapor exposure. Alcohol. Clin. Exp. Res. 28, 1676-1682. doi:10.1097/01.ALC.0000145781. 11923.4E

O'Malley, S. S., Krishnan-Sarin, S., Farren, C., Sinha, R., and Kreek, M. J. (2002). Naltrexone decreases craving and alcohol self-administration in alcohol-dependent subjects and activates the hypothalamopituitary-adrenocortical axis. Psychopharmacology (Berl.) 160, 19-29. doi:10.1007/s002130100919

Oomen, C. A., Mayer, J. L., de Kloet, E. R., Joels, M., and Lucassen, P. J. (2007). Brief treatment with the glucocorticoid receptor antagonist mifepristone normalizes the reduction in neurogenesis after chronic stress. Eur. J. Neurosci. 26, 3395-3401. doi:10.1111/j.14609568.2007.05972.x

Overstreet, D. H., Knapp, D. J., and Breese, G. R. (2004). Modulation of multiple ethanol withdrawalinduced anxiety-like behavior by CRF and CRF1 receptors. Pharmacol. Biochem. Behav. 77, 405-413. doi:10.1016/j.pbb.2003.11.010

Parent, J. M., Yu, T. W., Leibowitz, R. T., Geschwind, D. H., Sloviter, R. S., and Lowenstein, D. H. (1997). Dentate granule cell neurogenesis is increased by seizures and contributes to aberrant network reorganization in the adult rat hippocampus. J. Neurosci. 17, 3727-3738.

Pian, J. P., Criado, J. R., Milner, R., and Ehlers, C. L. (2010). $\mathrm{N}$-methyl-D-aspartate receptor subunit expression in adult and adolescent brain following chronic ethanol exposure. Neuroscience 170, 645-654. doi:10.1016/j.neuroscience.2010. 06.065
Prendergast, M. A., Harris, B. R., Mullholland, P. J., Blanchard, J. A. II, Gibson, D. A., Holley, R. C., et al. (2004). Hippocampal CA1 region neurodegeneration produced by ethanol withdrawal requires activation of intrinsic polysynaptic hippocampal pathways and function of N-methyl-D-aspartate receptors. Neuroscience 124, 869-877. doi:10.1016/j.neuroscience. 2003 . 12.013

Prendergast, M. A., and Mulholland, P. J. (2012). Glucocorticoid and polyamine interactions in the plasticity of glutamatergic synapses that contribute to ethanol-associated dependence and neuronal injury. Addict. Biol. 17, 209-223. doi:10.1111/j.13691600.2011.00375.x

Prior, P. L., and Galduroz, J. C. (2011). Glutamatergic hyperfunctioning during alcohol withdrawal syndrome: therapeutic perspective with zinc and magnesium. Med. Hypotheses 77, 368-370. doi:10.1016/j.mehy.2011.05.017

Rainnie, D. G., Bergeron, R., Sajdyk, T. J., Patil, M., Gehlert, D. R., and Shekhar, A. (2004). Corticotrophin releasing factor-induced synaptic plasticity in the amygdala translates stress into emotional disorders. J. Neurosci. 24, 3471-3479. doi:10.1523/JNEUROSCI.574003.2004

Recinto, P., Samant, A. R., Chavez, G., Kim, A., Yuan, C. J., Soleiman, M., et al. (2012). Levels of neural progenitors in the hippocampus predict memory impairment and relapse to drug seeking as a function of excessive methamphetamine self-administration. Neuropsychopharmacology 37, 1275-1287. doi:10.1038/npp.2011.315

Refojo, D., Schweizer, M., Kuehne, C., Ehrenberg, S., Thoeringer, C., Vogl, A. M., et al. (2011). Glutamatergic and dopaminergic neurons mediate anxiogenic and anxiolytic effects of CRHR1. Science 333, 1903-1907. doi:10.1126/science.1202107

Ren, J., Li, X., Zhang, X., Li, M., Wang, Y., and Ma, Y. (2013). The effects of intra-hippocampal microinfusion of d-cycloserine on fear extinction, and the expression of NMDA receptor subunit NR2B and neurogenesis in the hippocampus in rats. Prog. Neuropsychopharmacol. Biol. Psychiatry 44, 257-264. doi:10.1016/j.pnpbp.2013.02.017

Rice, A. C., Bullock, M. R., and Shelton, K. L. (2004). Chronic ethanol consumption transiently reduces adult neural progenitor cell proliferation. Brain Res. 1011,94-98. doi:10.1016/j.brainres.2004.01.091

Richardson, H. N., Chan, S. H., Crawford, E. F., Lee, Y. K., Funk, C. K., Koob, G. F., et al. (2009). Permanent impairment of birth and survival of cortical and hippocampal proliferating cells following excessive drinking during alcohol dependence. Neurobiol. Dis. 36, 1-10. doi:10.1016/j.nbd.2009.05.021

Richardson, H. N., Lee, S. Y., O’Dell, L. E., Koob, G. F., and Rivier, C. L. (2008). Alcohol selfadministration acutely stimulates the hypothalamic-pituitary-adrenal axis, but alcohol dependence leads to a dampened neuroendocrine state. Eur. J. Neurosci. 28, 1641-1653. doi:10.1111/j.14609568.2008.06455.x

Rimondini, R., Sommer, W., and Heilig, M. (2003). A temporal threshold for induction of persistent alcohol preference: behavioral evidence in a rat model of intermittent intoxication. J. Stud. Alcohol 64, 445-449.

Roberto, M., Nelson, T. E., Ur, C. L., and Gruol, D. L. (2002). Longterm potentiation in the rat hippocampus is reversibly depressed by chronic intermittent ethanol exposure. J. Neurophysiol. 87, 2385-2397.

Sahay, A., Scobie, K. N., Hill, A. S., O'Carroll, C. M., Kheirbek, M. A., Burghardt, N. S., et al. (2011). Increasing adult hippocampal neurogenesis is sufficient to improve pattern separation. Nature 472, 466-470. doi:10.1038/nature09817

Sajdyk, T. J., and Gehlert, D. R. (2000). Astressin, a corticotropin releasing factor antagonist, reverses the anxiogenic effects of urocortin when administered into the basolateral amygdala. Brain Res. 877, 226-234. doi:10.1016/S00068993(00)02638-X

Sajdyk, T. J., Schober, D. A., Gehlert, D. R., and Shekhar, A. (1999). Role of corticotropin-releasing factor and urocortin within the basolateral amygdala of rats in anxiety and panic responses. Behav. Brain Res. 100, 207-215. doi:10.1016/S01664328(98)00132-6

Sanna, E., Serra, M., Cossu, A., Colombo, G., Follesa, P., Cuccheddu, T., et al. (1993). Chronic ethanol intoxication induces differential effects on GABAA and NMDA receptor function in the rat brain. Alcohol. Clin. Exp. Res. 17, 115-123. doi:10.1111/j.15300277.1993.tb00735.x

Schmidt-Hieber, C., Jonas, P., and Bischofberger, J. (2004). Enhanced synaptic plasticity in newly generated granule cells of the adult hippocampus. Nature 429, 184-187. doi:10.1038/nature02553

Sheela Rani, C. S., and Ticku, M. K. (2006). Comparison of chronic ethanol and chronic intermittent ethanol treatments on the expression of GABA(A) and NMDA receptor subunits. Alcohol 38, 89-97. doi:10.1016/j.alcohol.2006.05.002

Shors, T. J., Townsend, D. A., Zhao, M., Kozorovitskiy, Y., and Gould, E. (2002). Neurogenesis may relate to some but not all types of hippocampal-dependent learning. Hippocampus 12, 578-584. doi:10.1002/hipo.10103

Smith, M. A., Weiss, S. R., Berry, R. L., Zhang, L. X., Clark, M., Massenburg, G., et al. (1997). Amygdalakindled seizures increase the expression of corticotropin-releasing factor (CRF) and CRF-binding protein in GABAergic interneurons of the dentate hilus. Brain Res. 745, 248-256. doi:10.1016/S00068993(96)01157-2

Snell, L. D., Nunley, K. R., Lickteig, R. L., Browning, M. D., Tabakoff, B., and Hoffman, P. L. (1996). Regional and subunit specific changes in NMDA receptor mRNA and immunoreactivity in mouse brain following chronic ethanol ingestion. Brain Res. Mol. Brain Res. 40, 71-78. doi:10.1016/0169-328X(96)00038-1

Snyder, J. S., Soumier, A., Brewer, M., Pickel, J., and Cameron, H. A. (2011). Adult hippocampal neurogenesis buffers stress responses and depressive behaviour. Nature 476, 458-461. doi:10.1038/nature10287

Sommer, W. H., Rimondini, R., Hansson, A. C., Hipskind, P. A., Gehlert, D. R., Barr, C. S., et al. (2008) Upregulation of voluntary alcohol intake, behavioral sensitivity to stress, and amygdala crhrl expression following a history of dependence. Biol. Psychiatry 63, 139-145. doi:10.1016/j.biopsych.2007.01.010

Sullivan, E. V., Fama, R., Rosenbloom, M. J., and Pfefferbaum, A. (2002). A profile of neuropsychological deficits in alcoholic women. Neuropsychology 16, 74-83. doi:10.1037/0894-4105.16.1.74

Sullivan, E. V., Marsh, L., Mathalon, D. H., Lim, K. O., and Pfefferbaum, A. (1995). Anterior hippocampal volume deficits in nonamnesic, aging chronic alcoholics. Alcohol. Clin. Exp. Res. 19, 110-122. doi:10.1111/j.15300277.1995.tb01478.x

Sullivan, E. V., Rosenbloom, M. J., and Pfefferbaum, A. (2000a). Pattern of motor and cognitive 
deficits in detoxified alcoholic men. Alcohol. Clin. Exp. Res. 24, 611-621. doi:10.1111/j.15300277.2000.tb02032.x

Sullivan, E. V., Rosenbloom, M. J., Lim, K. O., and Pfefferbaum, A. (2000b). Longitudinal changes in cognition, gait, and balance in abstinent and relapsed alcoholic men: relationships to changes in brain structure. Neuropsychology 14, 178-188. doi:10.1037/0894-4105.14.2.178

Taffe, M. A., Kotzebue, R. W., Crean, R. D., Crawford, E. F., Edwards, S., and Mandyam, C. D. (2010). Long-lasting reduction in hippocampal neurogenesis by alcohol consumption in adolescent nonhuman primates. Proc. Natl. Acad. Sci. U.S.A. 107, 11104-11109. doi:10.1073/pnas.0912810107

Tsai, G., Gastfriend, D. R., and Coyle, J. T. (1995). The glutamatergic basis of human alcoholism. Am. J. Psychiatry 152, 332-340.

Valdez, G. R., Roberts, A. J., Chan, K., Davis, H., Brennan, M., Zorrilla, E. P., et al. (2002). Increased ethanol self-administration and anxiety-like behavior during acute ethanol withdrawal and protracted abstinence: regulation by corticotropin-releasing factor. Alcohol. Clin. Exp. Res. 26, 1494-1501. doi:10.1111/j.15300277.2002.tb02448.x

Vendruscolo, L. F., Barbier, E., Schlosburg, J. E., Misra, K. K., Whitfield, T. W. Jr., Logrip, M. L., et al. (2012). Corticosteroiddependent plasticity mediates compulsive alcohol drinking in rats. J. Neurosci. 32, 7563-7571. doi:10.1523/JNEUROSCI.006912.2012
Wand, G. (2005). The anxious amygdala: CREB signaling and predisposition to anxiety and alcoholism. J. Clin. Invest. 115, 2697-2699. doi:10.1172/JCI26436

Wang, H. L., Tsai, L. Y., and Lee, E. H. (2000). Corticotropin-releasing factor produces a protein synthesis - dependent long-lasting potentiation in dentate gyrus neurons. $J$. Neurophysiol. 83, 343-349.

Wayner, M. J., Chitwood, R., Armstrong, D. L., and Phelix, C. (1997). Ethanol affects hypothalamic neurons projecting to the hippocampus and inhibits dentate granule cell LTP. Alcohol 14, 1-7. doi:10.1016/S07418329(96)00077-8

Weiner, J. L., Dunwiddie, T. V., and Valenzuela, C. F. (1999). Ethanol inhibition of synaptically evoked kainate responses in rat hippocampal CA3 pyramidal neurons. Mol. Pharmacol. 56, 85-90.

Wilce, P. A., Le, F., Matsumoto, I., and Shanley, B. C. (1993). Ethanol inhibits NMDA-receptor mediated regulation of immediate early gene expression. Alcohol. Alcohol Suppl. 2, 359-363.

Wilkins, L. H. Jr., Prendergast, M. A., Blanchard, J., Holley, R. C., Chambers, E. R., and Littleton, J. M. (2006). Potential value of changes in cell markers in organotypic hippocampal cultures associated with chronic EtOH exposure and withdrawal: comparison with NMDA-induced changes. Alcohol. Clin. Exp. Res. 30, 1768-1780. doi:10.1111/j.15300277.2006.00210.x

Wirkner, K., Poelchen, W., Koles, L., Muhlberg, K., Scheibler, P., Allgaier, C., et al. (1999). Ethanol-induced inhibition of NMDA receptor channels. Neurochem. Int. 35, 153-162. doi:10.1016/S0197-0186 (99)00057-1

Wright, J. W., Kramar, E. A., Myers, E. D., Davis, C. J., and Harding, J. W. (2003). Ethanol-induced suppression of LTP can be attenuated with an angiotensin IV analog. Regul. Pept. 113, 49-56. doi:10.1016/S0167-0115(02) 00302-6

Wu, P. H., Mihic, S. J., Liu, J. F., Le, A. D., and Kalant, H. (1993). Blockade of chronic tolerance to ethanol by the NMDA antagonist, (+)-MK-801. Eur. J. Pharmacol. 231, 157-164. doi:10.1016/00142999(93)90444-M

Yan, X. X., Toth, Z., Schultz, L., Ribak, C. E., and Baram, T. Z. (1998). Corticotropin-releasing hormone (CRH)-containing neurons in the immature rat hippocampal formation: light and electron microscopic features and colocalization with glutamate decarboxylase and parvalbumin. Hippocampus 8, 231-243. doi:10.1002/(SICI)10981063(1998)8:3\&lt;231::AIDHIPO6\&gt;3.0.CO;2-M

Zahr, N. M., Mayer, D., Vinco, S. Orduna, J., Luong, R., Sullivan, E. V., et al. (2009). In vivo evidence for alcohol-induced neurochemical changes in rat brain without protracted withdrawal, pronounced thiamine deficiency, or severe liver damage. Neuropsychopharmacology 34, 1427-1442. doi:10.1038/npp.2008.119

Zarrindast, M. R., Meshkani, J., Rezayof, A., Beigzadeh, R., and Rostami, P. (2010). Nicotinic acetylcholine receptors of the dorsal hippocampus and the basolateral amygdala are involved in ethanol-induced conditioned place preference. Neuroscience 168, 505-513. doi:10.1016/j.neuroscience.2010. 03.019

Zorrilla, E. P., Valdez, G. R., and Weiss, F. (2001). Changes in levels of regional CRF-like-immunoreactivity and plasma corticosterone during protracted drug withdrawal in dependent rats. Psychopharmacology (Berl.) 158, 374-381. doi:10.1007/s002130100773

Conflict of Interest Statement: The authors declare that the research was conducted in the absence of any commercial or financial relationships that could be construed as a potential conflict of interest.

Received: 05 February 2013; accepted: 12 June 2013; published online: 27 June 2013.

Citation: Mandyam CD (2013) The interplay between the hippocampus and amygdala in regulating aberrant hippocampal neurogenesis during protracted abstinence from alcohol dependence. Front. Psychiatry 4:61. doi: 10.3389/fpsyt.2013.00061

This article was submitted to Frontiers in Addictive Disorders and Behavioral Dyscontrol, a specialty of Frontiers in Psychiatry.

Copyright (c) 2013 Mandyam. This is an open-access article distributed under the terms of the Creative Commons Attribution License, which permits use, distribution and reproduction in other forums, provided the original authors and source are credited and subject to any copyright notices concerning any third-party graphics etc. 